\title{
1. Introduction: knowledge-intensive entrepreneurship in low-tech industries
}

\section{Hartmut Hirsch-Kreinsen and Isabel Schwinge}

\subsection{THE DEBATE ON KNOWLEDGE-INTENSIVE ENTREPRENEURSHIP}

The ongoing discussion over knowledge-intensive entrepreneurship (KIE) underscores its relevance to future economic growth and societal wellbeing (Audretsch et al., 2002; Malerba, 2010; Malerba and McKelvey, 2010). Moreover, this term is narrowly linked to the discourse on the emerging 'knowledge economy' and the debate on entrepreneurial activities. Heretofore research on KIE has mainly focused on firms or start-ups in the new technology-based high-tech sector. Altogether KIE is a vital mechanism for economic renewal, giving rise to new industries but also driving renewal within existing industries. The latter function of industrial revitalization, in particular, makes KIE an important phenomenon for the mature low-tech sector.

The overall objective of this volume is to introduce the discussion over KIE into the context of low-tech industries. The authors contributing to this book address diverse aspects - from characteristics and impacts (Part I), to specific strategies (Part II), all the way to political and policy preconditions (Part III) for KIE in this specific industrial context. Thereby different foci and approaches are applied to the KIE phenomenon that can be subsumed best by Malerba's (2010: 5) broad perspective on KIE as 'new innovators in a technology or sector that can be either de novo entrants or established firms active in a process of technological diversification'.

Initially a more detailed definition of KIE is outlined by its main features (Section 2). To start from a common ground, the relevance of and differences in the low-tech dimension at the sectoral and firm level are re-elaborated (Section 3). Following this an introduction of, first, constraints and opportunities for KIE in low-tech industries build the starting point for distinguishing this phenomenon from other sectoral 
contexts (Sections 4 and 5) before the structure of the volume is presented (Section 6).

\subsection{THE MAIN FEATURES OF KNOWLEDGE- INTENSIVE ENTREPRENEURSHIP}

The volume follows a broad concept of KIE, especially that based on Malerba (2010) and Malerba and McKelvey (2010), the following characteristic features of which are briefly outlined here.

The first feature of KIE refers to the organizational form of innovation activities (Malerba and McKelvey, 2010: 7). This relates to entrepreneurship as undertaking new activities and innovation as creating new economic value. This follows a Schumpeterian approach arguing that a fundamental change in existing activities as well as the introduction of entirely novel activities should keep providing the 'fuel' to the capitalist engine. Thus, KIE is considered an activity dealing with the uncertainties of discovering and exploiting new opportunities, often driven by individuals but also by established organizations in terms of 'corporate entrepreneurship'. The latter organizational form is thought to be particularly relevant with respect to the institutional context and constraints of low-tech industries.

The second feature of KIE is knowledge, which is primarily defined in relation to scientific, engineering and design knowledge. As Malerba explains (2010: 6 et seq.), this special notion of knowledge refers to systematic problem-solving knowledge, which is very different from that having a primary emphasis on experience and skills. Therefore entrepreneurs are considered to be 'knowledge operators' dedicated to the innovative utilization of existing knowledge, the new integration and coordination of different knowledge assets, and the creation of new knowledge aimed at the implementation of new products and technologies. Thus, KIE means the launch of new activities and organizations that intensively use existing scientific and technological knowledge, or that intensively create new scientific and technological knowledge for commercial purposes or for bringing new products or services to markets. In consequence, the 'absorptive capability' of entrepreneurs or - in the case of KIE as corporate entrepreneurship - of firms is a necessary condition. And, an increasing share of the workforce that is scientifically educated is thought to be one of the main preconditions for successful KIE activities.

The third feature is that KIE is shaped by systems of innovation that differ among sectors (Malerba, 2010: 8 et seq.). Networks, as relations to commercial and non-commercial actors, are regarded as a key prerequisite for entrepreneurship. They offer essential sources of knowledge, 
new capital, new potential employees, strategic alliance partners, and service providers (lawyers, accountants, consultants). Also networks allow entrepreneurs to share information and their assessments of markets and technologies. In addition to looking at business organizations, this network perspective analyses the contribution of universities, research organizations and other types of organizations to the emergence of KIE; particularly in academic organizations where knowledge from scientific research is assumed to generate new technologies for commercial exploitation. Also, users and suppliers may be a source of entrepreneurship and innovation in various ways, generally through knowledge related to market opportunities and customer demands. In addition, this view of innovation systems reconsiders the role of institutions as a key factor shaping entrepreneurship (ibid.: 12). Institutions include norms, routines, common habits, established practices, rules, laws, standards and so on, which shape the entrepreneurs' cognition and action and affect their interactions with other agents. Institutions and related organizations differ greatly in terms of their types of effect on the behavior of entrepreneurs. These effects can range from those that bind or impose constraints on KIE, to those that are created by interactions among agents (such as contracts) - from formal to informal (such as patent laws or specific regulations vs. traditions and conventions). Many institutions are national (such as the patent system), while others are specific to sectoral innovation systems related to industries, such as industry-specific labor markets or financial institutions. In general, these industry-specific institutions and knowledge-intensive entrepreneurs that are active in different contexts affect KIE as well.

The fourth feature of KIE refers to opportunities for innovation (Malerba and McKelvey, 2010: 8 et seq.). An innovation opportunity is here defined as the possibility to realize the economic value inherent in a new combination of resources and market needs. Opportunities can emerge from changes in the scientific or technological knowledge base, customer preferences, or the interrelationships between economic actors. The concept of innovative opportunities comprises both aspects related to the demand as well as to the scientific and technological knowledge needed to serve this specific market. The individual entrepreneurs or entrepreneurial firm must be able to identify the value to a customer, mobilize the resources and capture the economic benefits from innovating. This feature of KIE thus focuses the attention on organizational processes.

As aforementioned, entrepreneurship research still concentrates distinctly on the high-tech sector. However, in more recent debate on KIE, scholars underscore that KIE cannot be exclusively limited to high-tech industries. Rather, the KIE phenomenon is seen to emerge in different sectoral contexts (Malerba and McKelvey, 2010: 9). That means sectoral 
conditions greatly affect the opportunities of KIE through divergent stocks of knowledge, specific technological domains, different agents and networks, specific market conditions and institutional regulations. As a consequence, the patterns, opportunities and determining factors of KIE are highly sector-specific and the possibilities for growth are affected in very different ways. It seems that the exploration of low-tech specific characteristics of KIE has just begun.

\subsection{THE 'LOW-TECH’ DIMENSION}

\subsubsection{The Relevance of Low-Tech Industries}

The term 'low-technology' (low-tech) sector denotes those industries that have low-level or no research and development capacities and do not spend large amounts of money on R\&D activities. The basis of this categorization is the 'R\&D intensity' indicator, which measures the ratio of the R\&D expenditure to the turnover of a company or to the output value of an industry. By means of this indicator, industries with an R\&D intensity of more than 5 per cent on average are characterized as 'high-tech', and those with an R\&D intensity between 3 and 5 per cent as 'medium-hightech', or 'complex technologies'. ${ }^{1}$ Sectors with an R\&D intensity between 3 and 0.9 per cent are classified as 'medium-low-tech' and those with an R\&D intensity below 0.9 per cent as 'low-tech'. All these classed industries are further aggregated in the high-tech sector or the low-tech sector and the medium sectors respectively (cf. Table 1.1). In the following, the term 'low-tech industries' refers to both 'low- and medium-low-technology' (LMT) sectors. Regarding the industry level, industries such as household appliance manufacture, the food industry, the paper, publishing and print industry, the wood and furniture industry and the manufacture of metal products - such as the foundry industry - as well as plastic products manufacturing are grouped in LMT sectors. In contrast, pharmaceuticals, the electronics industry, medical engineering and vehicle construction, the aerospace construction industry as well as large parts of the mechanical engineering and the electrical industries are aggregated in high-tech and medium-high-tech (HMT) sectors (OECD, 2005).

Recent years have seen a growing body of innovation literature devoted to the innovativeness of low-tech industries. This research interest is mainly motivated by criticism of the mainstream of innovation research and innovation policy which regards a high investment in R\&D and advanced technologies as the key to growth and prosperity. This has led to the almost exclusive focus of many scholars and policy-makers on the economic 
Table 1.1 Classification of manufacturing industries into categories based on $R \& D$ intensity

\begin{tabular}{|c|c|}
\hline High-tech industries & Medium-high-tech industries \\
\hline $\begin{array}{l}\text { Aircraft and spacecraft } \\
\text { Pharmaceuticals } \\
\text { Office, accounting and computing } \\
\text { machinery } \\
\text { Radio, television and communications } \\
\text { equipment } \\
\text { Medical, precision and optical } \\
\text { instruments }\end{array}$ & $\begin{array}{l}\text { Electrical machinery and apparatus, n.e.c. } \\
\text { Motor vehicles, trailers and semi-trailers } \\
\text { Chemicals excluding pharmaceuticals } \\
\text { Railroad equipment and transport } \\
\text { equipment } \\
\text { Machinery and equipment }\end{array}$ \\
\hline Medium-low-tech industries & Low \\
\hline $\begin{array}{l}\text { Building and repairing of ships and } \\
\text { boats } \\
\text { Rubber and plastics products } \\
\text { Coke, refined petroleum products and } \\
\text { nuclear fuel } \\
\text { Other non-metallic mineral products } \\
\text { Basic metals and fabricated metal } \\
\text { products }\end{array}$ & $\begin{array}{l}\text { Manufacturing, n.e.c.; Recycling } \\
\text { Wood, pulp, paper, paper products, } \\
\text { printing and publishing } \\
\text { Food products, beverages and tobacco } \\
\text { Textiles, textile products, leather and } \\
\text { footwear }\end{array}$ \\
\hline
\end{tabular}

Note: n.e.c.: not elsewhere covered.

Source: OECD (2011).

sectors of high R\&D intensity, while the economic importance and specific innovative ability of LMT sectors is overlooked. Contrastingly, low-tech research as a whole has clearly shown that LMT firms and industries are by no means technologically and economically stagnant. LMT industries play a decisive role in shaping current economic structures and are essential to the future economic and technological development of advanced countries (Robertson et al., 2009). In other words, the surprising viability of the non-research-intensive industrial sectors in the developed economies of Western countries up to the present day cannot be ignored.

The large share that LMT industries contribute to the value added of the whole of manufacturing industry is a convincing indicator of this. In 2010 this share accounted for about 53 per cent in EU-27, while the respective share of HMT sectors was around 47 per cent; the high-tech sector stood at 12 per cent. ${ }^{2}$ The share of employment is another important indicator. In relation to the manufacturing industry as a whole, the LMT sectors in the EU-27 had an employment share of approximately 65 per cent in 2010 . 
The respective share of the HMT sectors accounted for about 35 per cent; the high-tech sector, only 7 per cent. ${ }^{3}$ The development of the different sectors in the EU-27 has been characterized by different trajectories in recent years. Annual average growth rates between 2005 and 2011 were negative for the LMT sectors - between -0.4 and -0.7 per cent - whereas the respective figures for HMT sectors were between 1.0 and 3.3 per cent. ${ }^{4}$ However, these data also underscore the relative high stability of the LMT sectors in the EU.

\subsubsection{Differentiations between Sectoral and Firm Level}

As low-tech research shows, the term 'LMT' does not sufficiently define the sectoral system. At least three aspects should be taken into consideration in dealing with LMT companies and sectors in further research activities. First, while this concept may be useful with regard to a first statistical definition, the term 'traditional industries' probably more appropriately specifies the industrial structure in question. To describe it one has to add further specifications. For example, the industries of these sectors are characterized by well-established technologies and production regimes. They have undergone a shorter or longer evolution, resulting in the emergence of established standards, methods and knowledge related to both products and processes. In other words, these industries are mostly well advanced along their industrial life cycles. This is perhaps one of the most important reasons for the difficult competitive position of many of these industries in Europe: the basic technologies and procedures relevant in the industries are well known and can often be easily copied by foreign competitors with a lower cost base. Another consequence of the established character of the technologies is that the technological change is predominantly incremental. Radical innovations based on fundamentally new scientific findings or erratic shifts in buyers' preferences can happen but are an unusual event in traditional industries. This applies to both products and processes. Consequently, growth rates in these industries are relatively low (EuroStat, 2013a; Jaegers et al., 2013).

Second, when speaking about LMT we should differentiate between the sectoral and the company level. At the sectoral level there are typical lowtech industries characterized by a low level of R\&D intensity. However, at the company level the situation is not so clear. Empirical data show that there are LMT companies (with low levels of R\&D intensity) in typical HMT sectors such as the pharmaceutical industry or mechanical engineering and - vice versa - high-tech companies in typical LMT sectors. These findings show that there are industries with fewer and industries with more low-tech companies, the latter being the above-mentioned low-tech indus- 
tries (Kirner et al., 2009). Therefore the area of research on entrepreneurship in the context of LMT should discriminate between 'entrepreneurial activities in industries dominated by LMT companies' and 'research on LMT companies'.

\subsection{CONSTRAINTS ON KIE IN LMT SECTORS}

Because of the structural conditions of LMT firms and sectors, the constraints on KIE activities in this field seem to be significant. The main features of KIE are considered to be the focus on unexploited opportunities, having to deal with uncertainties, the creation of new knowledge and the necessity of overcoming established routines on the company and sectoral level (Cohendet and Llerena, 2010). However, the context of LMT sectors and firms would seem to offer only very limited opportunities for these activities. The reason for this is that innovations in LMT sectors are known to be path-dependent and based on a relatively slow accumulation of capabilities surrounding previously known technological specializations. This path-dependency is continuously stabilized by incremental innovation activities, by increasing returns as the result of the continuously optimized processes in the existing technologies, and the therefore slowly emerging momentum of these developmental paths. ${ }^{5}$ As available research findings show, this holds true in particular for entrepreneurial activities in the context of established companies (Parhankangas and Arenius, 2003). Unlike the high-tech sector with its prevailing technological contingency, the technologies of the LMT sectors are well known and established, and the processes and products are not only highly standardized and routinized but also often rather advanced in complexity. The same holds for the knowledge base, which includes mostly codified, transferable and wellknown elements such as design methods, engineering routines or the knowhow of markets and customer preferences. Therefore technological norms, methods and leitmotifs as well as occupations and skills are well developed and have existed for many generations in these mature industries.

Furthermore, sales market conditions do not trigger KIE activities. The reason is that these conditions are mainly characterized by strong international competition based on prices and costs, forcing companies to optimize continuously their processes and technologies rather than pursuing risky innovation activities. In other words, the economic success of LMT companies is normally linked to professionalized managers whose job it is to optimize, rationalize in economies of scale and streamline the processes of their companies along the given trajectories in order to meet the needs of the intensive price competition on the internationalized sales markets. 
Thus, the chances for carrying out knowledge-intensive entrepreneurial experimentation in the aforementioned sense are limited by the fixed technological trajectories of LMT sectors and the cost uncertainties they may entail. ${ }^{6}$ To sum up, it cannot be denied that unlike the field of hightechnology, the socio-technical field of LMT industries offers relatively few opportunities to step up economic success. Aggregated economic data on growth rates and the development of employment in LMT industries convincingly prove this (Jaegers et al., 2013). From this perspective one has to admit that 'valuable opportunities' (Radosevic, 2010) for KIE in LMT are greatly limited.

\subsection{OPPORTUNITIES FOR KIE IN LMT SECTORS}

However, the constructive tendencies that accompany opportunities for KIE in low-tech should not be overlooked either. Theoretically it can be argued that - paradoxically - the situation of a fixed path-dependency can stimulate new ideas and, by attempts to overcome the obstacles they present, new paths can be created. The majority of actors involved may look upon new ideas and inventions as a cul-de-sac, but for a minority of economic actors this situation offers opportunities with a high potential for economic success (Deutschmann, 2008). It may also be argued that competitive pressure forces managers to change their role by adopting an increasingly reflective approach towards established practices and to look for breakthrough innovations (Beckert, 1991). This reflective approach may be triggered by a situation in which formerly increasing returns may cease to increase or even decrease (Deeg, 2005: 173). That may be caused in turn by continuously intensifying market competition and growing pressure from low-cost competitors. Generally it can be assumed that the intensive competitive pressure on low-tech industries forces actors not only to adopt managerial strategies of cost cutting and optimizing existing routines, but may also compel them to adopt a reflective stance towards the established practices in order to overcome this situation. Especially because of the great persistence and stability of LMT industries, entrepreneurial activities and a successful deviation from established practices and technological paths promise competitive advantage and high profitability. ${ }^{7}$

Recent research findings show that opportunities for KIE in LMT industries do in fact exist. Among these are, first, some long-term empirical studies which show that knowledge diversification tends to prevail over a mere deepening of the existing technological paths (Mendonça, 2009), and also draw attention to the overall surprising stability of LMT industries in many OECD countries (Kaloudis et al., 2005). From this it may be 
concluded that, usually, research findings have tended to underestimate the true extent and depth of entrepreneurial change in traditional businesses (Mendonça, 2009: 479).

Second, recent findings of case-study research emphasize the specific innovation ability of the low-tech sector and its companies (von Tunzelmann and Acha, 2005; Hirsch-Kreinsen, 2008). According to these findings, LMT companies very often not only pursue incremental innovation strategies but also try to overcome the routine paths of their knowledge and technology use through more far-reaching innovation activities such as architectural or modular innovation strategies. In part, such companies explicitly pursue strategies aiming at a leading position in niche markets beyond the main fields of standardized mature products or even try to create new market segments.

Third, research findings show the impressive success of so-called 'gazelles', e.g. fast-growing companies, often from the low-tech sector, which induce sectoral growth and create new jobs and new markets. Such companies can be found both in Western countries and in particular in the countries of Middle and Eastern Europe (Yudanov, 2007). ${ }^{8}$

These first findings can be interpreted as indicators for existing KIE processes in LMT sectors. However, even so the prerequisites, the mechanisms and, generally, the distinctive features of KIE in the low-tech context are still rather unclear.

\subsection{THE STRUCTURE OF THIS VOLUME}

These still open issues will be discussed in the following chapters from various methodological angles. Whereas Malerba (2010) and his contributors mainly applied quantitative analysis, the important contribution of case studies to this complex field of research is illustrated by McKelvey and Lassen's (2013) recent collection of case studies on KIE. A particular feature of our volume on the other hand is the broad mix of quantitative and qualitative methods that is necessary to deepen the understanding of the interplay between the emergence of KIE and the context of LMT sectors and/or firms (in the case of corporate entrepreneurship).

In Part I the question of the characteristics and patterns of, and the impact of KIE activities on LMT industries is broached. First, Yannis Caloghirou, Aimilia Protogerou and Aggelos Tsakanikas show in their contribution that KIE can also exist in the traditional industries of LMT sectors (Chapter 2). On the basis of a quantitative analysis of data from the large-scale AEGIS Survey they examine specific KIE characteristics in LMT sectors and posit similarities and differences to those of high- and 
medium-technology sectors. In this way they try to shed some light on the features of KIE in LMT firms and at the same time reveal some characteristics in common with high-tech companies which may help managers, policy-makers and scholars to better understand this 'high-potential' type of entrepreneurship.

Then, Hartmut Hirsch-Kreinsen specifies these findings on the empirical basis of case-study research on KIE processes in LMT sectors in different European countries (Chapter 3). He first presents a conceptual framework on KIE processes in LMT sectors as a guideline for the interpretation of empirical findings. Then he outlines four patterns of KIE in LMT sectors. These patterns represent distinguishable types of the opportunities and determining factors of KIE which describe and explain similarities and differences amongst KIE activities in LMT industries. This typology leads to an understanding of the determining factors, firm behavior and directions of KIE processes in LMT industries in this still mainly uninvestigated field of innovation research.

In Chapter 4 Ioanna Kastelli and Yannis Caloghirou present their findings on how KIE impacts the competitiveness and growth of European traditional industries. The authors argue that KIE in LMT sectors can contribute to overcoming competitive pressures from low-wage economies because it builds on knowledge-intensive assets, promotes innovation and continuous technological upgrading, and can also create new economic value by exploiting knowledge bases 'belonging' to other industries or scientific fields that use widely applicable knowledge. This topic has also important policy implications. Fostering the application of key enabling technologies in interactions between developers and users of these technologies can boost competitiveness. In addition, development of absorptive and technology management capabilities in these industries can transform them into knowledge-intensive users.

In Part II the contributions reveal prospects of knowledge-intensive activity in LMT industries by addressing different (country-) specific perspectives on business strategies and relations. Ricardo Mamede, Teresa Fernandes and Manuel Godinho illustrate in Chapter 5 how trademarks are used by various types of firms to differentiate their products. Their chapter provides the first results drawn from an integrated database that crosses information on national trademark applications with micro-data on all the firms with employees in Portugal. The main patterns of trademark use are identified and the characteristics of firms that are typically associated with trademark use are examined. The results indicate that trademark use is not primarily dependent on the knowledge intensity of the industries the firms belong to but rather on certain individual characteristics of the firms. An implication for the more innovative firms operat- 
ing in the low-tech and less knowledge-intensive industries is that the use of trademarks may be an option to reinforce their innovative strategies.

In Chapter 6 Andrei Yudanov deals with the widespread phenomenon of firms termed 'gazelle', i.e. those showing rapid growth over a long period of time. Surprisingly, gazelle-type firms can be found not only in high-tech but also in LMT sectors, especially in countries undergoing rapid economic change processes. The author presents the findings of an empirical study of gazelle firms in Russia. He outlines how in the first decades of the post-socialist development the existing R\&D-oriented way of developing KIE almost disappeared for Russian firms because of the catastrophic decrease in state demand for high-tech production and the destruction of the former vertically integrated national innovation system. Internal structural changes began to develop in Russia mainly as LMT-type - or gazelletype - businesses. These operations were to a lesser degree connected with inventive activity than with adaptation to, recombination and/or system integration of the world experience in Russia.

The authors Aimilia Protogerou, Yannis Caloghirou and Glykeria Karagouni then discuss the 'dynamic capabilities' perspective in lowtech industries in Chapter 7. Using extensive quantitative and qualitative data, the authors explore the relationship between dynamic capabilities (DCs) and firm performance measures in the novel context of young entrepreneurial ventures in LMT industries. In this way more light is shed on the still open issue of whether DCs have a role to play in an environment which by definition is characterized as stable but lacking in any significant amount of innovation. Rich survey data reveal how dynamic capabilities have a positive impact on diverse performance measures, indicating that they can indeed play a significant role in lowtech industries. The authors show convincingly that DCs are present in knowledge-intensive low-tech firms; however, their development appears to be sector-dependent and deeply impacted by the individual firms' evolutionary paths and choices.

In the concluding chapter of this part Isabel Schwinge aims to readjust the prevalent perspective on LMT firms in product supply chains in the debate on low-tech innovations and knowledge intensity (Chapter 8). In addition to the established perspective of 'supplier-dominated LMT firms', the supplying LMT firms and their interactions with customers are also considered as well as their internal knowledge activity. For this reason the analysis of empirical findings draws on the interaction model of the Industrial Marketing and Purchasing Group (IMP) and extends it to include the dimension of distributed knowledge bases. Different positions of LMT firms in product supply chains are presented, whereby recourse to qualitative case studies from the AEGIS project sheds light on 
knowledge-intensive activity of LMT companies with regard to sources of knowledge and the conditions for extending knowledge bases.

In Part III of the volume, policy implications of the findings on KIE activities in LMT industries are summarized and some necessary requirements of policy measures are discussed. Attila Havas examines policy strategies in a conceptual manner (Chapter 9). He juxtaposes the analyses of innovation in mainstream economics vis-à-vis evolutionary economics of innovation, as well as their concomitant policy rationales. By discussing the indicators selected for the Innovation Union Scoreboard and another major EU report, he argues that the 'science-push' model of innovation is still highly influential in policy circles, despite a rich set of research insights stressing the importance of non-R\&D types of knowledge in innovation processes. In conclusion, the chapter highlights the potential drawbacks of the persistent high-tech myth, considers possible reasons for its perseverance and discusses policy implications of the systemic view of innovation. One of them is that STI policies should promote knowledge-intensive activities in all sectors, including LMT industries and services.

The concluding chapter to this volume, offered by Hartmut HirschKreinsen and Isabel Schwinge, outlines policy recommendations for the promotion of KIE in low-tech industries (Chapter 10). The authors reveal that KIE activities in LMT sectors have received only limited support from public measures and policy so far. This situation is consistent with the limited awareness of the importance of policy for traditional industries in general. Despite this, promising fields of action are emerging for policies to promote KIE in low-tech industries. These include improving access to distributed, trans-sectoral knowledge, promoting activities that improve the specific capabilities of LMT firms, policy measures that better target the needs of KIE in LMT sectors, particularly the funding of start-up activities, and a generally increased awareness and better understanding of innovation processes in low-tech industries. The authors argue that there are considerable opportunities for pushing forward KIE activity and improving the severe competitive situation of many LMT firms despite the strong path-dependency of traditional industries and their technologies.

\section{NOTES}

1. This indicator covers in-house $R \& D$ expenditures on $R \& D$ staff, further $R \& D$ costs and investments as well as out-of-house expenditures, e.g. on R\&D tasks assigned to other companies and organizations (OECD, 2002: 108).

2. EuroStat,http://epp.eurostat.ec.europa.eu/statistics_explained/index.php/High-technology_ versus_low-technology_manufacturing (accessed 19 September 2013).

3. Our own approximation based on: EuroStat, Structural Business Statistics 'sbs_na_sca_ 
r2', http://epp.eurostat.ec.europa.eu/portal/page/portal/european_business/data/database (accessed June 2013).

4. EuroStat,http://epp.eurostat.ec.europa.eu/statistics_explained/index.php/High-technology_ versus_low-technology_manufacturing (accessed 19 September 2013).

5. See the concept of path-dependency in social sciences and innovation theory (Garud and Karnøe, 2003). In this perspective incremental innovations can be regarded as 'small events' not changing but only stabilizing existing paths.

6. Whereas a manager orients his decisions on routines, adaptation and imitation, entrepreneurs are characterized by a reflective stance towards taken-for-granted scripts and existing institutional regulations - following Schumpeter's distinction between the manager and the entrepreneur (Schumpeter, 1997: 110).

7. This argument refers to the debate in organizational sociology on 'institutional entrepreneurship' which reintroduces agency, interests and power into an institutional analysis of organizational change (Beckert, 1991; Garud and Karnøe, 2003; Garud et al., 2002).

8. See also Yudanov in this volume (Chapter 6).

\section{REFERENCES}

Audretsch, D., B. Bozeman, K. Combs, M. Feldman, A. Link, D. Siegel, P. Stephan, G. Tassey and C. Wessner (2002), 'Economics of Science and Technology', Journal of Technology Transfer, 27 (2), 155-203.

Beckert, J. (1991), 'Agency, Entrepreneurs and Institutional Change: The Role of Strategic Choice and Institutionalized Practices in Organizations', Organizational Studies, 20 (5), 777-99.

Cohendet, Patrick and Patrick Llerena (2010), 'The Knowledge-Based Entrepreneur: The Need for a Relevant Theory of the Firm', in Franco Malerba (ed.), Knowledge-Intensive Entrepreneurship and Innovation Systems: Evidence from Europe, London, UK and New York, USA: Routledge, pp. 31-51.

Deeg, Richard (2005), 'Change from Within: German and Italian Finance in the 1990s', in Wolfgang Streeck and Kathleen Thelen (eds), Beyond Continuity: Institutional Change in Advanced Political Economies, Oxford, UK: Oxford University Press, pp. 169-204.

Deutschmann, Christoph (2008), Kapitalistische Dynamik: Eine gesellschaftstheoretische Perspektive, Wiesbaden: VS-Verlag.

EuroStat (2013a), 'High-Technology versus Low-Technology Manufacturing', available at http://epp.eurostat.ec.europa.eu/statistics_explained/index.php/ High-technology_versus_low-technology_manufacturing (accessed 19 September 2013).

EuroStat (2013b), 'Structural Business Statistics: sbs_na_sca_r2', Luxembourg: European Commission, available at http://epp.eurostat.ec.europa.eu/portal/ page/portal/european_business/data/database (accessed June 2013).

Garud, R. and P. Karnøe (2003), 'Bricolage versus Breakthrough: Distributed and Embedded Agency in Technology Entrepreneurship', Research Policy, 32 (2), 277-300.

Garud, R., S. Jain and A. Kumaraswamy (2002), 'Institutional Entrepreneurship in the Sponsorship of Common Technological Standards: The Case of Sun Microsystems and Java', Academy of Management Journal, 45 (1), 196-214.

Hirsch-Kreinsen, H. (2008), “'Low-Tech” Innovation', Industry and Innovation, 15 (1), 19-43. 
Jaegers, T., C. Lipp-Lingua and D. Amil (2013), 'High-Technology and MediumHigh Technology Industries Main Drivers of EU-27's Industrial Growth', Eurostat Statistics in focus, 1 (2013), available at http://epp.eurostat.ec.europa. eu/cache/ITY_OFFPUB/KS-SF-13-001/EN/KS-SF-13-001-EN.PDF (accessed 15 August 2013).

Kaloudis, Aris, Tore Sandven and Keith Smith (2005), 'Structural Change, Growth and Innovation: The Roles of Medium and Low Tech Industries, 1980-2000', in Gerd Bender, David Jacobson and Paul L. Robertson (eds), Non-ResearchIntensive Industries in the Knowledge Economy, published in Perspectives on Economic, Political and Social Integration, XI (1-2), special issue, 49-74.

Kirner, E., S. Kinkel and A. Jaeger (2009), 'Innovation Paths and the Innovation Performance of Low-Technology Firms - An Empirical Analysis of German Industry', Research Policy, 38 (3), 447-58.

Malerba, Franco (2010), Knowledge-Intensive Entrepreneurship and Innovation Systems: Evidence from Europe, London, UK and New York, USA: Routledge.

Malerba, F. and M. McKelvey (2010), 'Conceptualizing Knowledge Intensive Entrepreneurship: Concepts and Models', paper presented at the DIME AEGIS - LIEE/NTUA Athens 2010 Conference, 29-30 April 2010.

McKelvey, Maureen and Astrid Heidemann Lassen (eds) (2013), How Entrepreneurs Do what They Do: Cases Studies in Knowledge Intensive Entrepreneurship, Cheltenham, UK and Northampton, MA, USA: Edward Elgar.

Mendonça, S. (2009), 'Brave Old World: Accounting for "High-Tech" Knowledge in "Low-Tech" Industries', Research Policy, 38 (3), 470-82.

OECD (2002), OECD Frascati Manual: Proposed Standard for Surveys on Research and Experimental Development, 6th edition, Paris: OECD.

OECD (2005), Oslo-Manual, Proposed Guidelines for Collecting and Interpreting Technological Innovation Data, 3rd edition, Paris: OECD.

OECD (2011), 'ISIC REV. 3 Technology Intensity Definition - Classification of Manufacturing Industries into Categories Based on R\&D Intensities', available at www.oecd.org/sti/ind/48350231.pdf (accessed 21 May 2012).

Parhankangas, A. and P. Arenius (2003), 'From a Corporate Venture to an Independent Company: A Base for a Taxonomy for Corporate Spin-off Firms', Research Policy, 32 (3), 463-81.

Radosevic, Slavo (2010), 'What Makes Entrepreneurship Systemic?', in Franco Malerba (ed.), Knowledge-Intensive Entrepreneurship and Innovation Systems: Evidence from Europe, London, UK and New York, USA: Routledge, pp. 52-76.

Robertson, P.L., K. Smith and N. von Tunzelmann (2009), 'Innovation in Lowand Medium-Technology Industries', Research Policy, 38 (3), 441-6.

Schumpeter, Joseph (1997/1934), Theorie der wirtschaftlichen Entwicklung, Berlin: Duncker \& Humblot.

Von Tunzelmann, Nick and Virginia Acha (2005), 'Innovation in "Low-Tech" Industries', in Jan Fagerberg, David C. Mowery and Richard R. Nelson (eds), The Oxford Handbook of Innovation, New York, USA: Oxford University Press, pp. 407-32.

Yudanov, A. (2007), 'Fast-Growing Firms and the Evolution of the Russian Economy', Problems of Economic Transition, 50 (8), 7-28. 